\title{
Laparoscopic Management of Gastrointestinal Stromal Tumors: Nine Patients with Different Locations and Presentations: Retrospective Study
}

\author{
Ahmed Hussein Abdelhafez, MD; Mohammed Shaaban Khalifa, MD; \\ Mohammed Mostafa Marzouk, MD.
}

\author{
Department of General Surgery, Faculty of Medicine, Ain Shams University.
}

Background: Laparoscopic management of gastrointestinal stromal tumors (GISTs) is safe and effective. It is considered to be the preferred technique offered to the patient. Laparoscopic wedge resection has been widely accepted for small-and medium-sized GISTs. The use of laparoscopic approach should be based on a variety of factors including: patient characteristics, tumor size, and presence of invasion, location of tumor, surgeon and laparoscopic expertise.

Patients and methods: Total number of nine patients with GISTs who presented to our unit from January 2010 till May 2015 were retrospectively reviewed. Patients' demographics, clinical data, intraoperative and postoperative complications, and histopathological data were analyzed. Most lesions were resected via a wedge technique with closure of defect either by an endoscopic linear stapling device or intracorporeal suturing technique.

Results: Nine patients who presented with GISTs underwent laparoscopic resection according to its position and size. The median age at diagnosis was 48 years old, and average tumor size was $4.2 \mathrm{~cm}$ with the largest tumor measuring $7.5 \mathrm{~cm}$. There was no episode of tumor rupture or spillage and no major intraoperative or postoperative complications. All margins were negative, mean follow up was 14.4 (range 8.5-15.2) months. Majority of lesions were resected via laparoscopic wedge resection except one case (female patient aged 48 years old) that presented with GIST located at the gastric fundus, this patient underwent proximal (partial gastrectomy) and another case (adult male 26 years old) that presented with upper rectal GIST was managed via laparoscopic anterior resection. There was no evidence of metastasis or recurrence except in the patient who had been presented with rectal GIST.

Conclusion: Laparoscopic resection is safe and effective for GISTs not exceeding $6 \mathrm{~cm}$. Gastroesophageal junction and cardia GISTs require careful preoperative evaluation and planning to be removed safely. Laparoscopic removal is currently the surgical treatment of choice for patients with primary localized GISTs, and open surgery is not even considered unless there are contraindications to the laparoscopic approach.

Key words: Minimally invasive surgery, gastrointestinal stromal tumors, laparoscopic wedge resection.

\section{Introduction:}

Gastrointestinal stromal tumors (GISTs) are the most common mesenchymal neoplasms of the gastrointestinal (GI) tract. ${ }^{1}$ The reported annual incidence in Western Sweden is about $10-20$ cases per 1 million individuals. ${ }^{2}$ These tumors occur in patients of all ages, with a median age of 55-60 years, affecting males and females at the same rate. ${ }^{3}$

GISTs most commonly occur in the stomach (50-70\% of cases), followed by the small intestine (20-30\% of cases). ${ }^{4-5}$ However, these tumors are found throughout the GI tract. Gastrointestinal stromal tumors of the esophagus, colon and rectum account for less than $10 \%$ of all cases. Uncommonly, 
they can arise within the greater omentum, appendix and gallbladder. ${ }^{4-5}$

The interstitial cells of Cajal, pleuropotential intestinal pacemaker cells, were identified as the origin of GISTs. ${ }^{6}$ The key characteristic of GIST is gain-of-function sporadic mutation within the genes coding for the tyrosine kinase receptors, which is supposed to be the driving force of cell proliferation in the GIST.7 Tyrosine kinase receptor (c-kit) is a transmembrane receptor that is activated by the binding of KIT protein, a c-kit proto-oncogene product. Up to $80 \%$ of GISTs have KIT protein mutations, while $8 \%$ have mutations in the platelet derived growth factor receptor a (PDGFRa), a-polypeptide gene encoding a c-kit homologous type III receptor tyrosine kinase protein. ${ }^{8}$ The essential ligand-independent activation of the mutated KIT protein results in imbalance between cell survival and proliferation, away from apoptosis. ${ }^{9}$ The specific immunohistochemical markers of the tumors are CD117 - 95\% positivity, CD34 - 70-80\% positivity,(smooth muscle actin) SMA - 20$30 \%$ positivity, and desmin $-<5 \%$ positivity. ${ }^{10}$

Most GISTs are diagnosed incidentally during diagnostic studies or investigation for non specific GIT symptoms. On abdominal computed tomography (CT) scan, a GIST typically appears as a hyperdense mass, closely associated with adjacent organs (stomach, small intestine). On up-per GIT endoscopy (EGD), a GIST usually looks like a submucosal mass with usually central ulceration. Endoscopic ultrasound (EUS) can define the layer of the stomach wall that gives rise to the tumor. EGD or EUS is an essential diagnostic modalities to obtain tissue for histological diagnosis, usually by core-needle biopsy or fine-needle aspiration (FNA). Moreover, these diagnostic methods can also help decide whether endoscopic removal of the tumor is possible. Localization of the GIST, following UGIE with biopsy or EUS with FNA, within the smooth muscle layer and gain of neoplastic spindle cells with mutations in the c-KIT or PDGFRa genes are pathognomonic features. Often, however, UGIE is non-contributory. 11
Better understanding of the nature of GISTs has enabled the development and application of targeted therapy. Such therapy, using tyrosine kinase inhibitors, has demonstrated efficiency in the treatment of metastatic and inoperable GISTs. Nevertheless, at this time surgical resection presents the only possibility of cure for primary localized GISTs. ${ }^{12}$

A complete surgical resection can be performed in up to $95 \%$ of these cases. The modern surgical treatment of GISTs combines the use of targeted therapy and aggressive minimally invasive surgery to provide effective treatment for this lethal Gl tumor. ${ }^{12}$ Tumor-free microscopic surgical margins and tumor size were demonstrated to be the most important prognostic factors determining survival. It is therefore accepted that the surgical goal should be a complete segmental or wedge resection with tumor-free margins only without routine lymphadenectomy for tumors whose size and location technically allow for it. ${ }^{13}$ However, the operative technique for complete surgical resection for primary solitary GISTs of various locations is at issue. Both open and minimally invasive operations have been shown to reduce recurrence rates and improve long-term survival. Retrospective series suggest that minimally invasive techniques may reduce perioperative stress and are associated with lower rates of postoperative complications, shorter hospital stays and equivalent recurrence rates. Maximum diameter of GIST for laparoscopic resection, however, is still not clearly defined. Moreover, GISTs located in proximity to the gastroesophageal junction (GEJ) or at the cardia can prove challenging to manage laparoscopically as the deformity after resection of such lesions can result in gastroesophageal reflux or late stenosis. Gastrointestinal stromal tumors involving the prepyloric part of the stomach have also been reported to be difficult to remove using minimally invasive technique. ${ }^{14}$

Advances in endoscopic technology have allowed attempted excision of GISTs and other gastric submucosal masses to be performed endoscopically. ${ }^{15}$ A combined laparoendoscopic approach has been reported in 
several series for resection of gastric GISTs, located in the gastroesophageal junction, cardia and posterior wall of the stomach. ${ }^{16,17}$ However, most of these studies have a small number of cases; therefore safety and efficacy of this treatment are not yet established. ${ }^{18}$

\section{Patient and methods:}

The medical records of 9 consecutive patients were reviewed retrospectively from the data base for all suspected GISTs to have undergone primary laparoscopic resection, from January 2010 to May 2015 diagnosis of all tumors was confirmed postoperatively by pathologists. Only patients presenting with primary solitary GISTs surgically resectable were selected. Patients were diagnosed and staged preoperatively through upper GI endoscopy, endoscopic ultrasound (EUS), biopsy, abdominal ultrasound (US), computed tomography (CT) with contrast or magnetic resonance imaging (MRI) Table (1).

Our surgical approach was based on perspective investigations and was determined by tumor size, location and growth characters (exophytic or endophytic). Patients were applicable for laparoscopic surgery with localized, non-metastatic, extramucosal tumors. Tumors candidate for resection with appropriate diameter and position which suggested resectability through segmental or wedge resection were dealt with. Data on patients' demographics, symptoms on presentation, preoperative tumor localizing studies, clinical course, laparoscopic procedure performed and operative outcome, operative time, histopathological features, and postoperative hospital stay were collected and analyzed. Histopathological features reviewed included resection marginal status, tumor size, mitotic rate, immunohistochemical marker status (CD 117, CD34, SMA, DES and S-100), and presence of ulceration and central necrosis of the tumor. Mitotic rate was defined as the number of mitoses per 50 high power field (HPF), and tumor size was defined as the maximum tumor diameter in the resected specimen.

For estimating the risk of aggressive behavior and disease progression, patients were stratified into four categories (very low, low, intermediate and high) according to the Fletcher et el classification; 2002 Table (2), based on tumor size and mitotic count, and into five categories (none, very low, low, intermediate and high) according to the Miettinen and Lasota classification, 2006 Table (3), based on tumor size, location and mitotic rate. These classifications consider rather different parameters; therefore we used both of them in order to detect any differences within, regarding symptoms on presentation, tumor location, mean maximum tumor diameter and surgical procedures performed.

All patients with confirmed high risk of aggressive GIST without spreading features were followed up regularly including UGIE and abdominal CT scan every 6 to 12 months. Vital status and tumor recur-rence were assessed.

Ethical consideration:

This study was subjected to ethical committee evaluation and was accepted for seek of patients benefit and research purposes' and all patients were notified about operative technique, and possible complications.

\section{Results:}

Patient characteristics:

Between January 2010 and May 2015, nine consecutive patients underwent laparoscopic surgical treatment for gastrointestinal stromal tumors. Laparoscopic resection was attempted successfully in all patients. There were 4 males (44.5\%) and 5 females (55.6\%). The median age was 48 years.

The most common symptom on presentation was upper GI bleeding (hematemesis) in 3 patients (33.4\%) followed by dysphagia in 2 patients who presented with esophageal GIST (22.4\%), bleeding per rectum in 2 patients (22.4\%)who presented with small intestinal GISTs Table (4) ,1 patient who presented with non-specific dyspeptic symptoms (11.2\%)such patient was presented with GIST at gastro esophageal junction (GEJ), 1 patient who presented with 
difficult defecation (progressive constipation) with upper rectal GIST (11.2\%).

\section{Diagnostic workup:}

The most common diagnostic method used was abdomino-pelvic CT scan with contrast in all patients (100\%) followed by upper GI endoscopy in 6 patients (2 esophageal GISTs, 4 gastric GISTs) (66.5\%) then colonoscopy in one patient (11.1\%), Histopathological diagnosis of tumor was confirmed preoperatively in 7 patients (77.7\%),upper GI endoscopy with biopsy was used in 6 patients (66.5\%) and colonoscopy with biopsy was used in one patient (11.1\%).

\section{Perioperative outcomes:}

All patients underwent laparoscopic wedge resection and closure of defect by either endoscopic linear stapling device or intracorporeal suture and placement of intraperitoneal drain according to surgeon preference. First one was a female patient presented with gastric GIST located at the fundus has been subjected to laparoscopic proximal (upper) gastrectomy with establishment of continuity by roux-en Y esophagojejunostomy and closure of distal gastric pouch with entero-enterostomy and the second patient who was a male aged 26 years old,was complaining of difficult defecation and investigated via pelviabdominal CT and colonoscopy with biopsy, and he underwent laparoscopic anterior resection with disease free interval of 2 years ,the patient received incomplete course of imatinab due to travelling abroad shortly after operation .The patient had recurrence of symptoms and reinvestigated when recurrent rectal GIST was discovered for which he underwent laparotomy and open resection, 3 years have elapsed and new recurrence ( $2^{\text {nd }}$ recurrence) has occurred for which the patient underwent relaparotomy and excision of multiple disseminated pelvic tumor deposits, patient had received imatinab mesylate in post-operative period, complete cure was obtained and no recurrence was noticed in 6 years follow up period.

Endoscopy was not used intraoperatively neither to specify the tumor location, nor to stain the tumor excision borders. Two patients had presented with esophageal GISTs (one male 38 years old, and one female patient 52 years old) at distal $1 / 3$ of esophagus have been subjected to laparoscopic wedge resection . 5th patient (28 years old) who presented with gastric GIST located at GEJ, such patient underwent excision of the tumor with anterior wrap fundoplication due to pre-operative reflux symptoms, no other additional or concurrent laparoscopic procedures had done. All high - risk patients had received imatinab mesylate postoperatively to minimize recurrence and improve survival. Characters of laparoscopic management of different GIST tumors were summarized in Table (5), according to tumor location, operation performed, and patient characteristics.

The mean tumor size was $4.2 \mathrm{~cm}$ (range $2.2 \mathrm{~cm}-7.5 \mathrm{~cm}$ ), the average operative time was $150 \pm 45$ minutes (range 105 - 195) minutes. The mean post-operative stay was 7.5 days ( 3 - 12 days). There were no postoperative complications and no mortalities.

Tumor location and histopathological characteristics:

There were $(44.4 \%) \quad(n=4)$ of tumors located in the stomach, followed by esophagus $(22.2 \%)(n=2)$. Small intestine (22.2\%) $(\mathrm{n}=2)$ and rectum $(11.1 \%)(\mathrm{n}=1)$. Esophageal GISTs were located at distal $1 / 3$ of esophagus, stomach GISTs were located in the body, the fundus, the lesser curvature, and close to the GEJ. Small intestinal GISTs were located close to the DJ flexure, and terminal ileum. One patient had large GIST in upper rectum aged 26 years old $(11.1 \%)(n=1)$.

Mucosal ulceration and central necrosis were found in all cases (100\%).

Histology was consistent with spindle cells in 4 patients (44.5\%), epithelioid cells in 3 patients (33.3\%), mixed in 2 patients (22.2\%). CD117 was positive in 4 patients (44.5\%), CD34 was positive in 6 patients (66.6\%) and desmin, S-100 and SMA were positive. There were 4 tumors of low risk malignancy located in small intestine (2 tumors) and esophagus (2 tumors) and 2 tumors of intermediate risk 


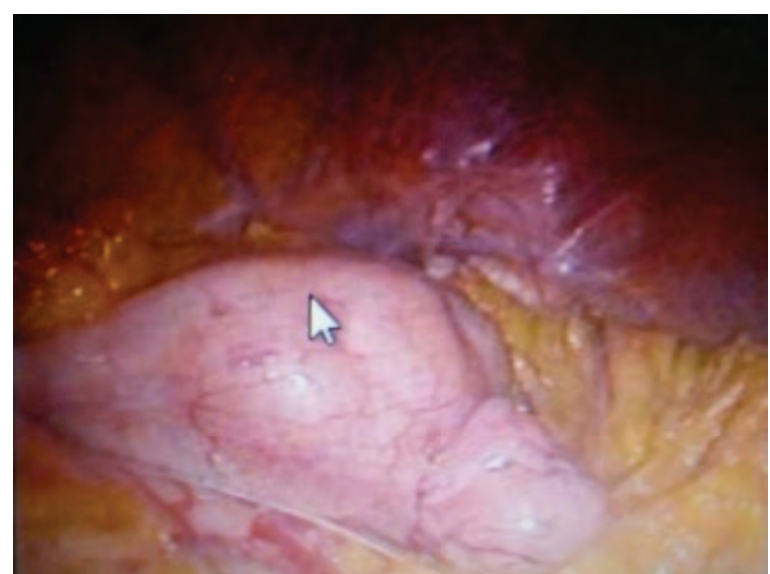

Figure (1): Laparoscopic view of gastric GIST located in the body of stomach.

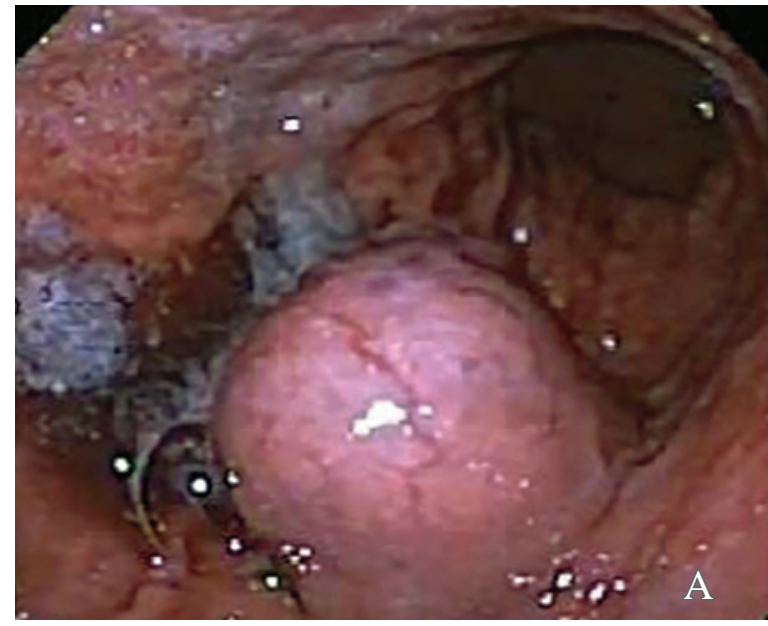

Figure (3): (A, B) Lap.wedge resection of gastric GIST.

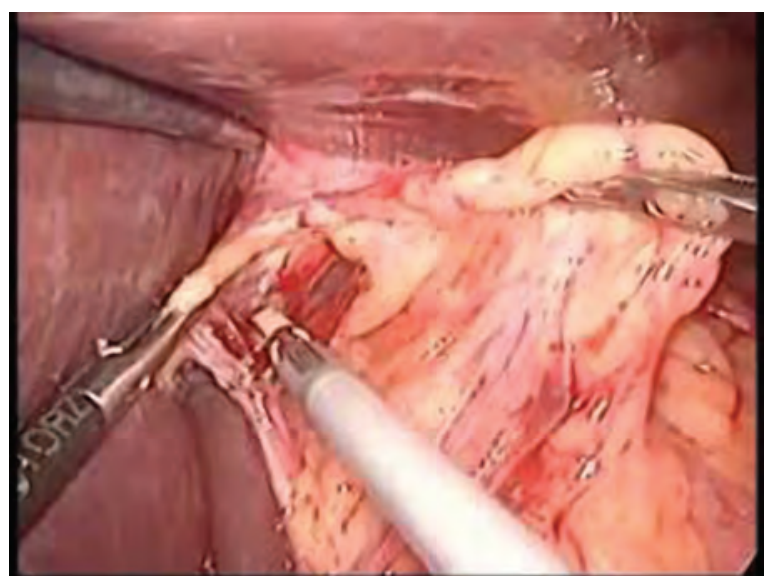

Figure (2): Laparoscopic dissection of lower esophageal GIST.

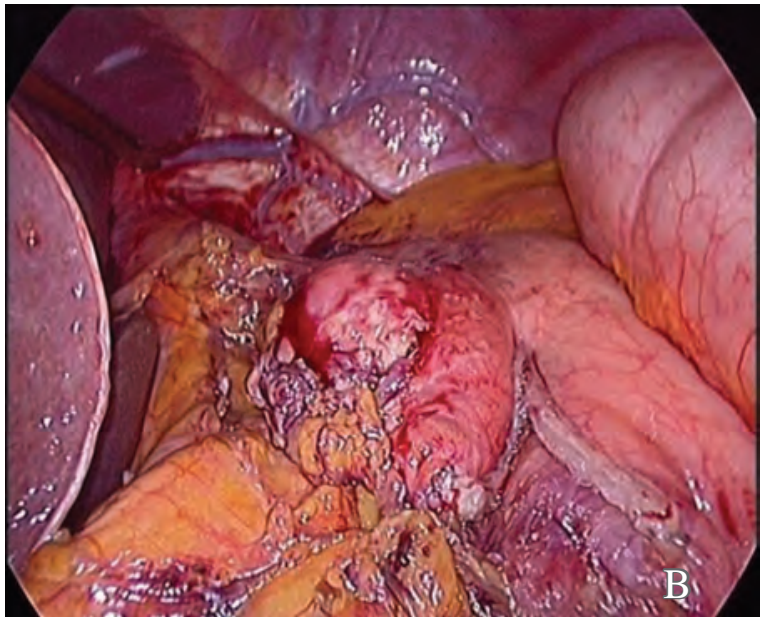

Figure (4):Endoscopic view of GIST located at GEJ.

(gastric body + GEJ) and 3 tumors were high risk (located in the fundus of stomach, lesser
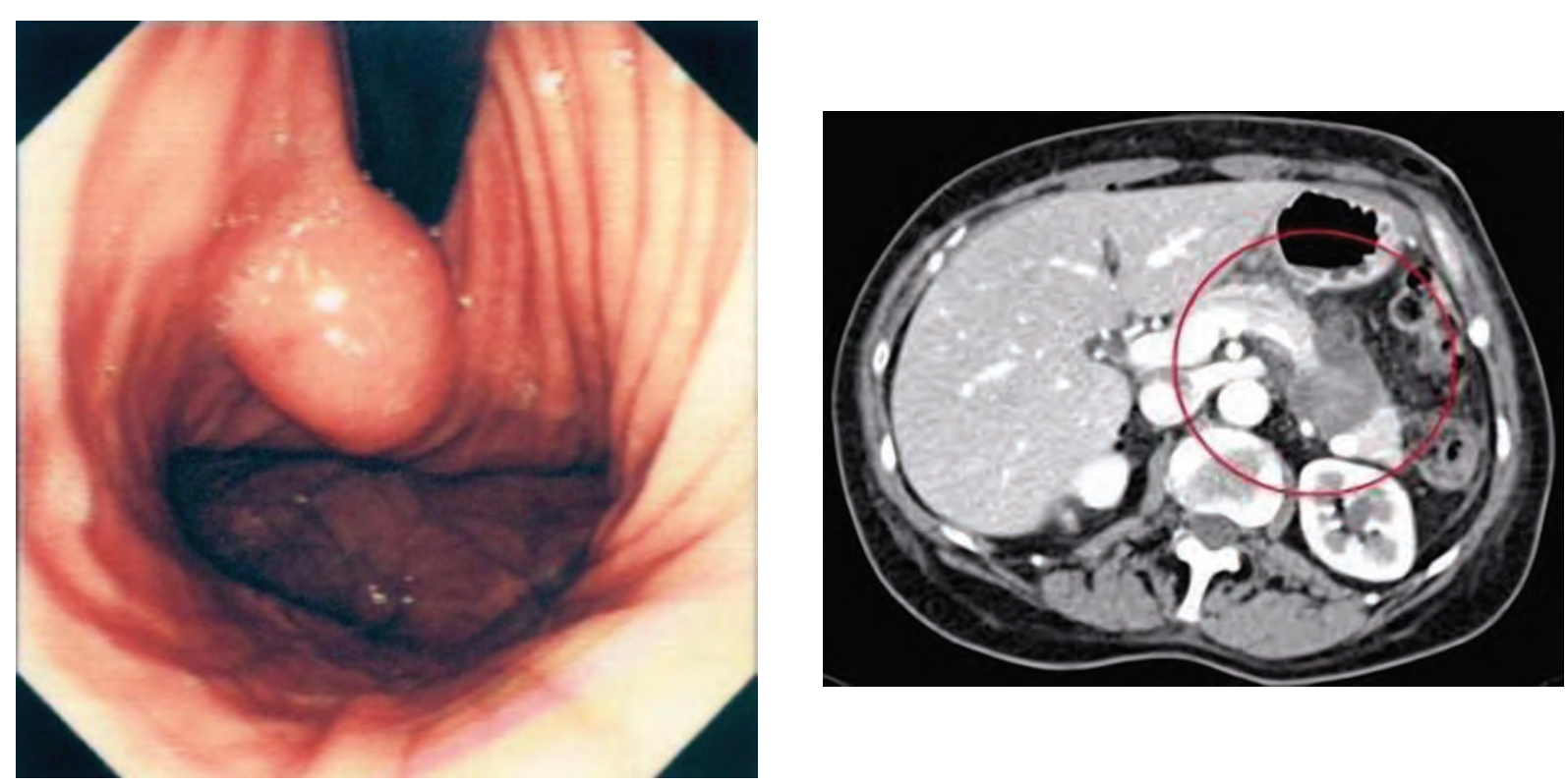

Figure (5): CT scan demonstrated a gastric GIST.

curvature, upper rectum). The mean follow up was $14.4 \pm 6.2$ months range $(8.5-25.2 \%$ 


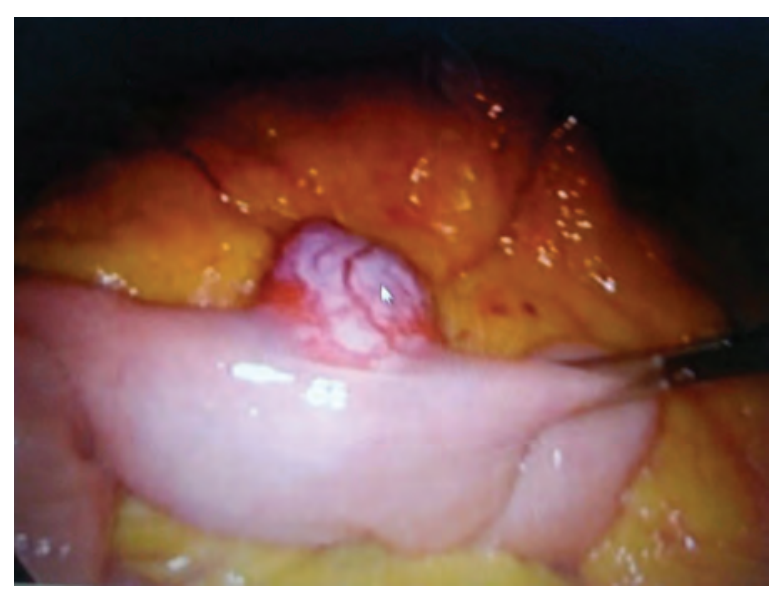

Figure (6): GIST in the jejunum.

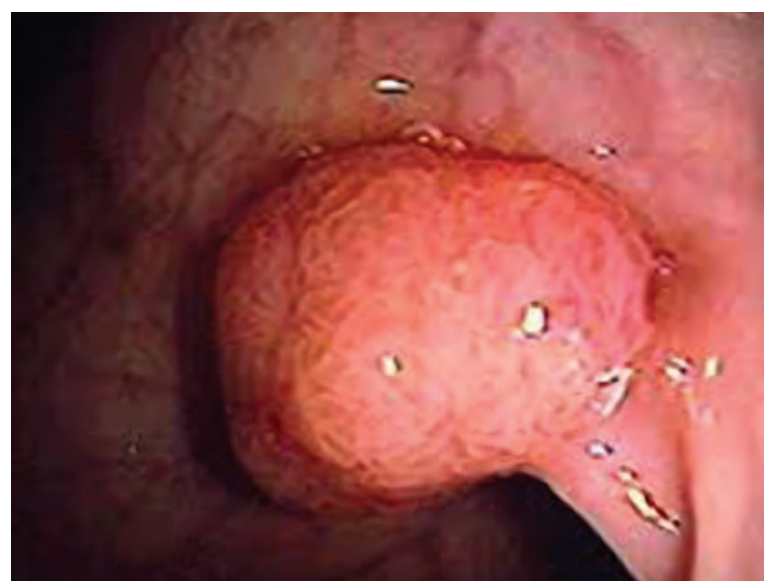

Figure (7): Endoscopic view of rectal GIST.

Table (I). Diagnostic characteristics of patients operated on for gastrointestinal stromal tumors.

\begin{tabular}{|l|l|}
\hline \multicolumn{1}{|c|}{ Diagnostic tool } & No and \% of pts \\
\hline Upper GIT endoscopy & $6(66.6 \%)$ \\
\hline EUS & $8(88.8 \%)$ \\
\hline FNAC & $7(77.7 \%)$ \\
\hline CT & $9(100 \%)$ \\
\hline US & $4(44.5 \%)$ \\
\hline MRI & $4(44.5 \%)$ \\
\hline CT angiography & $5(55.5 \%)$ \\
\hline Colonoscopy & $1(11.1 \%)$ \\
\hline
\end{tabular}

Table (2): Risk of aggressive behavior in GISTs.

\begin{tabular}{|l|l|l|}
\hline Risk & Size (largest dimension) $[\mathrm{cm}]$ & Mitotic count ( HPF) \\
\hline Very low & $<2$ & $<5 / 50$ \\
\hline \multirow{2}{*}{ low } & $2-5$ & $<5 / 50$ \\
\hline \multirow{2}{*}{ intermediate } & $<5$ & $6-10 / 50$ \\
\cline { 2 - 3 } & $5-10$ & $<5 / 50$ \\
\hline \multirow{2}{*}{ High } & $>5$ & $>5 / 50$ \\
\cline { 2 - 3 } & $>10$ & Any mitotic \\
\hline
\end{tabular}

months) Table (5).

\section{Discussion:}

Gastrointestinal stromal tumors are rare submucosal tumors that are recently becoming increasingly diagnosed because of the increasing usage of upper Gl endoscopy and abdominal CT scan, or perhaps because of the rising incidence of GISTs. Gastrointestinal stromal tumors represent approximately $80 \%$ of mesenchymal GIT tumors and less than $1 \%$ of all GIT malignancies. ${ }^{18}$

Gastrointestinal stromal tumors, although rare, are the most common mesenchymal tumor of the gastrointestinal tract. Lymph node metastases are very rare, and routine lymphadenectomy is not required. Wedge resection of gastric GISTs has been widely reported to be successful. The goal of surgical resection should be complete removal of the 
Table (3): Rates of metastases or tumor-related death in GISTs.

\begin{tabular}{|c|c|c|c|c|}
\hline \multirow{2}{*}{$\begin{array}{l}\text { Tumor parameters Mitotic } \\
\text { rate Tumor size }[\mathrm{cm}]\end{array}$} & \multicolumn{4}{|c|}{ Risk of progressive disease } \\
\hline & Gastric GISTs & \begin{tabular}{|l|} 
Jejunal and \\
ileal GISTs \\
\end{tabular} & $\begin{array}{l}\text { Duodenal } \\
\text { GISTs }\end{array}$ & Rectal GISTs \\
\hline $\begin{array}{l}<5 / 50 \mathrm{HPFs} \\
<2 \mathrm{~cm}\end{array}$ & None & None & None & None \\
\hline$>2 \mathrm{~cm}$ & \begin{tabular}{|l|} 
Very low $(1.9 \%)$ \\
\end{tabular} & Low (4.3\%) & Low (8.3\%) & Low (8.5\%) \\
\hline$>5 \mathrm{~cm}$ & Low (3.6\%) & $\begin{array}{l}\text { Moderate } \\
(24 \%)\end{array}$ & High (34\%) & High (57\%) \\
\hline$>10 \mathrm{~cm}$ & Moderate (12\%) & High (52\%) & & \\
\hline $\begin{array}{l}>5 / 50 \mathrm{HPFs} \\
<2 \mathrm{~cm}\end{array}$ & None & High (50\%) & $\operatorname{High}(50 \%)$ & High (54\%) \\
\hline$>2<5 \mathrm{~cm}$ & Moderate (16\%) & High (73\%) & High (50\%) & High (52\%) \\
\hline$>5 \mathrm{~cm}$ & High (55\%) & High (85\%) & High $(86 \%)$ & High (71\%) \\
\hline$>10 \mathrm{~cm}$ & High (86\%) & High (90\%) & & \\
\hline
\end{tabular}

Table (4): Clinical presentation regarding tumor location.

\begin{tabular}{|l|l|l|}
\hline \multicolumn{1}{|c|}{ Symptoms } & \multicolumn{1}{c|}{ Tumor location } & \multicolumn{1}{c|}{ No and \% of patients } \\
\hline $\begin{array}{l}\text { Upper GI bleeding } \\
\text { (hematemesis) }\end{array}$ & $\begin{array}{l}\text { Stomach (fundus, body, } \\
\text { lesser curvature) }\end{array}$ & $3(33.3 \%)$ \\
\hline Dysphagia & Esophagus & $2(22.2 \%)$ \\
\hline Dyspeptic symptoms & GEJ & $1(11.1 \%)$ \\
\hline Bleeding/rectum & Small intestine & $2(22.2 \%)$ \\
\hline Difficult defecation & Rectum & $1(11.1 \%)$ \\
\hline
\end{tabular}

tumor with clear resection margins. Because these tumors don't usually diffusely infiltrate the wall of the stomach, resection margins of $1-2 \mathrm{~cm}$ are usually sufficient. Tumor rupture during laparoscopy should be avoided as peritoneal seeding can affect the disease-free period and overall patient survival. ${ }^{19}$

Because GISTs are submucosal, regular endoscopic biopsies rarely provide pathologic confirmation. But now that C-kit testing can be performed on FNA specimens, and because FNA is associated with a very low risk of seeding, many GISTs can be diagnosed preoperatively using FNA. ${ }^{20}$

Reports from the 2004 National Comprehensive Cancer Network GIST Task Force and the GIST Consensus Conference under the auspices of the European society of Medical Oncology recommended that laparoscopic or laparoscopic-assisted resection may be used for small $(<2 \mathrm{~cm})$
GISTs. In our series, we demonstrated that GISTs larger than $2 \mathrm{~cm}$ can be safely removed laparoscopically (mean tumor size $3.2 \mathrm{~cm}$ in the current study) with oncological results similar to those obtained using an open technique. Other studies have also confirmed the feasibility and safety of laparoscopic resection of tumors measuring up to $5 \mathrm{~cm}$. the largest GISTs removed laparoscopically in our study measured $(6.8-7.5 \mathrm{~cm}){ }^{21-22}$

Gastrointestinal stromal tumors are rarely suspected before the time of surgery due to the low incidence of the disease. Asymptomatic tumors are usually discovered incidentally during UGIE, abdominal CT scan or as a secondary finding during unrelated abdominal surgery. A high rate of suspicion is necessary to make the right diagnosis. De Matteo (2002); reported a mean duration of symptoms of 6 months before establishing the diagnosis. ${ }^{21}$ Abdominal CT scan, following 
Table (5): Patient demography, tumor characters and laparoscopic procedure performed.

\begin{tabular}{|c|c|c|c|c|c|c|c|c|}
\hline & $\begin{array}{l}\text { Patient } \\
\text { sex }\end{array}$ & Age & $\begin{array}{l}\text { Tumor } \\
\text { location }\end{array}$ & $\begin{array}{l}\text { Tumor } \\
\text { size }\end{array}$ & $\begin{array}{l}\text { Mitotic } \\
\text { rate }\end{array}$ & $\begin{array}{l}\text { Risk } \\
\text { classificati-on }\end{array}$ & $\begin{array}{l}\text { Laporoscopic } \\
\text { procedure }\end{array}$ & $\begin{array}{l}\text { No and \% } \\
\text { of patients }\end{array}$ \\
\hline 1 & Male & 38 ys & $\begin{array}{l}\text { Lower } \\
\text { esophagus }\end{array}$ & $2.2 \mathrm{~cm}$ & $4 / 50$ & Low risk & $\begin{array}{l}\text { Wedge } \\
\text { resection }\end{array}$ & $1(11.1 \%)$ \\
\hline 2 & Female & 52 ys & $\begin{array}{l}\text { Lower } \\
\text { esophagus }\end{array}$ & $2.5 \mathrm{~cm}$ & $4 / 50$ & Low risk & $\begin{array}{l}\text { Wedge } \\
\text { resection }\end{array}$ & $1(11.1 \%)$ \\
\hline 3 & Female & 56 ys & $\begin{array}{l}\text { Stomach } \\
\text { body }\end{array}$ & $4.5 \mathrm{~cm}$ & $8 / 50$ & $\begin{array}{l}\text { Intermediat } \\
\text { risk }\end{array}$ & $\begin{array}{l}\text { Wedge } \\
\text { resection }\end{array}$ & 1 (11.1\%) \\
\hline 4 & Female & 48 ys & $\begin{array}{l}\text { Stomach } \\
\text { fundus }\end{array}$ & $7.5 \mathrm{~cm}$ & $18 / 50$ & High risk & \begin{tabular}{|l} 
Partial \\
gastrectomy \\
+ Roux-en \\
Y esophago \\
jejunostomy
\end{tabular} & $1(11.1 \%)$ \\
\hline 5 & Female & 28 ys & $\begin{array}{l}\text { Lesser } \\
\text { curvature }\end{array}$ & $6.5 \mathrm{~cm}$ & $14 / 50$ & High risk & $\begin{array}{l}\text { Wedge } \\
\text { resection }\end{array}$ & 1 (11.1\%) \\
\hline 6 & Male & 32 ys & GIJ & $4 \mathrm{~cm}$ & 7/50 & $\begin{array}{l}\text { Intermediat } \\
\text { risk }\end{array}$ & $\begin{array}{l}\text { Wedge } \\
\text { resection }+ \\
\text { fundoplication }\end{array}$ & 1 (11.1\%) \\
\hline 7 & Male & 51 ys & DJ flexure & $2 \mathrm{~cm}$ & $4 / 50$ & Low risk & $\begin{array}{l}\text { Wedge } \\
\text { resection }\end{array}$ & 1 (11.1\%) \\
\hline 8 & Female & 62 ys & $\begin{array}{l}\text { Terminal } \\
\text { ileum }\end{array}$ & $1.8 \mathrm{~cm}$ & $3 / 50$ & Low risk & $\begin{array}{l}\text { Wedge } \\
\text { resection }\end{array}$ & 1 (11.1\%) \\
\hline 9 & Male & 26 ys & $\begin{array}{l}\text { Upper } \\
\text { rectum }\end{array}$ & $6.8 \mathrm{~cm}$ & $22 / 50$ & High risk & $\begin{array}{l}\text { Anterior } \\
\text { resection }\end{array}$ & 1 (11.1\%) \\
\hline
\end{tabular}

UGIE or EUS is the best choice to assess the exact tumor location and size, and evaluate direct or metastatic spread. ${ }^{23-24}$

Biopsy or fine-needle aspiration, followed by UGIE or EUS, respectively, can aid in making the differential diagnosis of the GIT lesions. EUS with FNA frequently reveals spindle cells or may be positive for specific GIST markers. ${ }^{22}$ Sepe and his coworkers (2009); has shown that endoscopic fineneedle aspiration for the diagnosis of GIST has sensitivity as high as $80 \% .^{23}$

The latest 2010 European Society for MedicalOncology(ESMO)recommendations definitely consider surgical excision of tumors without preoperative histological diagnosis of GIST if they are of size $>2 \mathrm{~cm}$ or show an increase in size. ${ }^{24}$ The 2007 National Comprehensive Cancer Network Clinical Practice Guidelines in Oncology (NCCN guidelines) stated that preoperative biopsy is not appropriate in easily removable tumors and consider that it is important only if neo adjuvant targeted therapy is planned. ${ }^{24-25}$

Most patients present with a solitary primary tumor that is growing in an exophytic extraluminal way, which makes them easy to find. However, many of them are well confined by a thin surrounding pseudocapsule, which is very fragile. ${ }^{26}$ During laparoscopy, careful and minimal manipulation of the tumor by graspers or hands is necessary. If minimally invasive surgery is performed, it is advisable to place the tumor in a bag and to remove it through the skin incision. ${ }^{27}$

Laparoscopic stapling of the stomach for GIST resection may sometimes result in an excessive amount of normal gastric mucosa being removed. This in turn may cause stomach deformity and narrowing, particularly in areas such as the esophagogastric junction. The "new-shaped" stomach may also result in 
motility problems. A cut and sew technique might be superior to the use of staplers in these difficult areas to avoid the sacrifice of an excessive amount of normal gastric mucosa. Esophageal bougies can also be used before applying a stapler when the tumor is close to the GE junction. ${ }^{27-28}$

However, special attention should be paid to GEJ, cardia and prepyloric tumors, which are perhaps the most difficult tumor locations to approach via laparoscopic techniques because of the risk of narrowing ,and gastroesophageal reflux. ${ }^{29}$

Gastrointestinal stromal tumors are resistant to conventional chemotherapy and radiotherapy. Imatinab mesylate has proven useful in the treatment of recurrent or metastatic GISTs, and is now accepted as an adjuvant therapy after surgical resection. However, resistance to imatinab is a growing problem, and other targeted agents, such as sunitinab, are available. Until proven otherwise, complete excision with clear resection margins and without tumor rupture remains the mainstay of treatment for primary GISTs. ${ }^{30-31}$

Controversy surrounds the maximum diameter of GIST for laparoscopic removal. The 2007 NCCN guidelines propose that GISTs of sizes $<5 \mathrm{~cm}$ should be removed with the use of laparoscopy. Meanwhile, for GISTs of sizes $>5 \mathrm{~cm}$ hand-assisted laparoscopy should be indicated, because these tumors are more vascularized, more fragile, have a larger pseudocapsule, frequently occur with a necrotic component and frequently are found to be attached to adjacent structures. ${ }^{32-33}$

Several retrospective series have demonstrated that the laparoscopic approach is associated with low morbidity and mortality, and excellent oncologic outcomes. Our data show that the purely laparoscopic approach to local or segmental resections is amenable for GISTs located in the stomach or duodenum and results in effective control of the disease with minimal perioperative morbidity and no mortality. ${ }^{34}$

Laparoscopic removal is currently the surgical treatment of choice in patients with primary localized GISTs, and open surgery is not even considered unless there are contraindications to the laparoscopic approach. ${ }^{35}$

Small intestine GISTs have been reported to have a higher rate of complications compared to tumors of the stomach, ${ }^{35}$ although other studies have challenged this. We found no worse outcome associated with small bowel tumors. ${ }^{36-37}$

\section{Conclusion:}

In our study we consider laparoscopic resection to be safe and effective for GISTs not exceeding $6 \mathrm{~cm}$. Gastroesophageal junction and cardia GISTs require careful preoperative evaluation and planning to resect safely. The decision to perform preoperative biopsy should be individualized and only performed when the results of the specimen definitely determine the choice of treatment. ${ }^{28}$

Laparoscopic approach may be the preferred resection technique in most patients with small and medium sized GISTs. Larger GISTs in difficult anatomic locations may still require an open technique, as a formal gastric resection may be required. ${ }^{29}$

In spite of its difficulty and learning curve is slow and demanding, more data and large number of patients are needed to augment and enrich our statistics, increase the chance for better results ,and improve our outcome. Till this target to happen still our results and outcome not far from published series done and released from other minimally invasive centers worldwide.

All the laparoscopic procedures in our series perfomed by highly professional, and experienced laparoscopic surgeons with good results and minimal postoperative complications. So we advise to reach such excellent results to be performed by professional, well trained laparoscopic surgeons with advanced expertise.

\section{Reference:}

1- Corless CL, Fletcher JA, Heinrich MC: Biology of gastrointestinal stromal tumors. $J$ Clin Oncol 2004; 22: 3813-3825.

2- Nilsson B, Bumming P, Meis-Kindblom JM: Gastrointestinal stromal tumors: The incidence, prevalence, clinical course, and 
prognostication in the pre imatinib mesylate era - a population-based study in western Sweden. Cancer 2005; 103: 821-829.

3- Gold JS, Dematteo RP: Combined surgical and molecular therapy: The gastrointestinal stromal tumor model. Ann Surg 2006; 244: 176-184.

4- Miettinen M, Sobin LH, Lasota J: Gastrointestinal stromal tumors of the stomach: A clinicopathologic, immunohistochemical, and molecular genetic study of 1765 cases with long-term follow-up. Am J Surg Pathol 2005; 29: 52-68.

5- Iran T, Davila JA, El-Serag HB: The epidemiology of malignant gastrointestinal stromal tumors: An analysis of 1458 cases from 1992 to 2000. Am J Gastroenterol 2005; 100: 162-168.

6- Fletcher CD, Berman JJ, Corless C: Diagnosis of gastrointestinal stromal tumors: A consensus approach. Hum Pathol 2002; 33: 459-465.

7- Shinomura V, Kinoshita K, Tsutsui S: Pathophysiology, diagnosis, and treatment of gastrointestinal stromal tumors. J Gastroenterol 2005; 40: 775-780.

8- Sepe PS, Brugge WR: A guide for the diagnosis and management of gastrointestinal stromal cell tumors. Nat Rev Gastroenterol Hepatol 2009; 6: 363-371.

9- Rubin BP, Singer S, Tsao C: KIT activation is a ubiquitous feature of gastrointestinal stromal tumors. Cancer Res 2001; 61: 8118-8121.

10- Miettinen M, Lasota J: Gastrointestinal stromal tumors: Review on morphology, molecular pathology, prognosis, and differential Diagnosis. Arch Pathol Lab Med 2006; 130: 1466-1478.

11- Joensuu H, Roberts PJ, Sarlomo-Rikala: Effect of the tyrosine kinase inhibitor ST1571 in a patient with a metastatic gastrointestinal stromal tumor. $N$ Engl J Med 2001; 344: 1052-1056.

12- Roggin KK, Posner MC: Modern treatment of gastric gastrointestinal stromal tumors. World J Gastroenterol 2012; 18: 6720-6728.

13- Heinrich MC, Corless CL: Gastric Gl stromal tumors (GISTs): The role of surgery in the era of targeted therapy. J Surg Oncol 2005; 90: 195-207.

14- Pucci Ml, Berger AC, Lirn PW: Laparoscopic approaches to gastric gastrointestinal stromal tumors: An institutional review of 57 cases. Surg Endosc 2012; 26: 3509-3514.

15- Makarewicz W, Bobowicz M, Dubowik
M: Endoscopic sub-mucosal dissection of gastric ectopic pancreas. Video surgery Miniinv 2013; 8: 249-252.

16- Gayer CP, Edelman DA, Curtis B: Combined endoscopic and laparoscopic approach to a gastroesophageal tumor. JSLS 2011; 15 : 228-231.

17- Hiki N, Yamamoto Y, Fukunaga T: Laparoscopic and endoscopic cooperative surgery for gastrointestinal stromal tumor dissection. Surg Endosc 2008; 22: 1729-1735.

18- Wilhelm D, von Delius S, Burian M: Simultaneous use of laparoscopy and endoscopy for minimally invasive resection of gastric subepithelial masses - analysis of 93 interventions. World J Surg 2008; 32: 1021-1028.

19- Scarpa M, Berlin M, Ruffolo C: A systematic review on the clinical diagnosis of gastrointestinal stromal tumors. J Surg Oncol 2008; 98: 384-392.

20- Tryggvason G, Kristrnundsson T, Orvar K: Clinical study on gastrointestinal stromal tumors (GIST) in Iceland. 1990-2003. Dig Dis Sci 2007; 52: 2249-2253.

21- De Matteo RP: The GIST targeted cancer therapy: A tumor (gas-trointestinal stromal tumor), a mutated gene (c-kit), and a molecular inhibitor (STI571). Ann Surg Oncol 2002; 9: 831-839.

22- Novitsky YW, Kercher KW, Sing Rf: Longterm outcomes of laparoscopic resection of gastric gastrointestinal stromal tumors. Ann Surg 2006; 243: 738-747.

23- Sepe PS, Moparty B, Pitman MB: EUSguided FNA for the diagnosis of Gl stromal cell tumors: Sensitivity and cytologic yield. Gastrointest Endosc 2009; 70: 254-261.

24- Casali PG, Jost L, Reichardt P: Gastrointestinal stromal tumors: ESMO clinical recommendations for diagnosis, treatment and follow-up. Ann Oncol 2008; 19: 35-38.

25- Demetri GD, Benjamin RS, Blanke CD: NCCN Task Force report: Management of patients with gastrointestinal stromal tumor (GIST) - update of the NCCN clinical practice guidelines. 2007; 5: 21-29.

26- Gervaz P, Huber O, Morel P: Surgical management of gastrointestinal stromal tumours. Br J Surg 2009; 96: 567-578.

27- Everett M, Gutman H: Surgical management of gastrointestinal stromal tumors: Analysis of outcome with respect to surgical margins and technique. J Surg Oncol 2008; 98: 588-593. 
28- Basu S, Balaji S, Bennett DH: Gastrointestinal stromal tumors (GIST) and laparoscopic resection. Surg Endosc 2007; 21: 1685-1689.

29- Sakra L, Siller J, Vyhnalek P: Surgical treatment of gastric and small bowel gastrointestinal stromal tumors. Surg Endosc 2011; 6: 138-143.

30- Katoh T, Itoh Y, Mohri T: Endoscopic enucleation of gastro-intestinal stromal tumors of the stomach: Report of five cases. World J Gastroenterol 2008; 14: 2609-2611.

31- Taniguchi E, Kamiike W, Yamanishi H: Laparoscopic intra-gastric surgery for gastric leiomyoma. Surg Endosc 1997; 11: 287-289.

32- Everett M, Gutrnan H: Surgical management of gastrointestinal stromal tumors: Analysis of outcome with respect to surgical margins and technique. J Surg Oncol 2008; 98: 588-593.

33- Tabrizian P, Nguyen SQ, Divino CM:
Laparoscopic management and long-term outcomes of gastrointestinal stromal tumors. J Am Coll Surg 2009; 208: 80-86.

34- Sokolich J, Galanopoulos C, Dunn E: Expanding the indications for laparoscopic gastric resection for gastrointestinal stromal tumors. JSLS 2009; 13: 165-169.

35- Sexton JA, Pierce RA, Halpin VJ: Laparoscopic gastric resection for gastrointestinal stromal tumors. Surg EndosC 2008; 22: 2583-2587.

36- Nguyen SQ, Divino CM, Wang JL: Laparoscopic management of gastrointestinal stromal tumors. Surg Endosc 2006; 20: 713-716.

37- Keun PC, Lee EJ, Kim M: Prognostic stratification of high-risk gastrointestinal stromal tumors in the era of targeted therapy. Ann Surg 2008; 247: 1011-1018. 